\title{
Drag Reduction using Suction Slit to the Main Wing
}

\author{
VVN Harish, Bhargav.A and Ch.Praveen Kumar \\ Department of Aeronautical Engineering, Vardhaman College of Engineering, Shamshabad, R.R dist., A.P, India \\ Accepted 01 July 2016, Available online 11 July 2016, Vol.6, No.4 (Aug 2016)
}

\begin{abstract}
Boundary layers, however invisible to the naked eye, are a characteristic property found where the velocity of a fluid relative to a solid surface is nil, hence in the proximity of this surface a region of velocity increases gradually from nil to the free stream velocity. This has the undesirable effect of causing turbulent flow over long surfaces, which reduce the performance of moving solids by introducing frictional drag forces it has been noted that skin-friction drag is strongly intensified by the outset of turbulence, however, in turn this turbulence is also greatly strengthened by the flow separation. In addition, this laminar flow separation and skin-friction drag decrease lift effects or increases the pressure drag on the aerodynamic surfaces, resulting in decreased efficiency, increased fuel consumption. This research aims to reduce the boundary layer separation by introducing a suction slit to the wing at various positions of the wing and to compare the results with an un-suctioned airfoil. Computational technique is used to study the $L / D$ ratios of various cases and analysis of airfoils. This technique is very powerful and spans a wide range of applications.
\end{abstract}

Keywords: Boundary layer, suction slit, airfoil, L/D ratio, CFD (Computational Fluid Dynamics), GAMBIT, FLUENT.

\section{Introduction}

An airfoil is the shape of a wing or blade sail as seen in section. Such bodies when moving through the fluid produces aerodynamic forces such as Lift and Drag. Lift is the component that perpendicular to the free stream velocity and Drag is parallel to it. Foils with the same properties that were designed for the water as working fluid are called as hydrofoils.

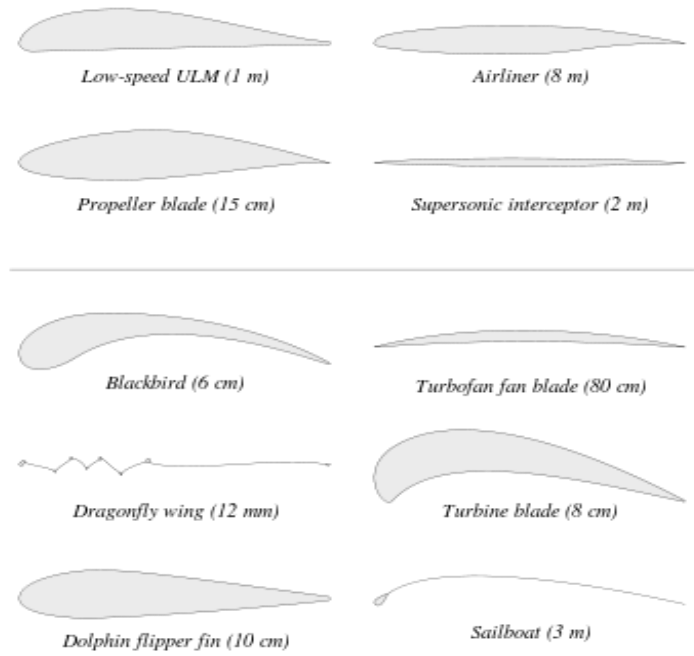

*Corresponding author Ch.Praveen Kumar is a Student; VVN Harish and Bhargav.A are working as Assistant Professors DOI: dx.doi.org/10.14741/Ijcet/22774106/6.4.2016.3
Fig.1: Types of Airfoils

The shape of the airfoil contributes to the amount of lift produced on it by creating the pressure distribution on the surfaces of the upper and lower surface. The lift force can also be related directly to the average top/bottom velocity difference without calculating the pressure difference by the concept of circulation and Kutta-Jukowski theorem.

Airfoils are the efficient lifting shapes that are able to generate more lift with low drag. Airfoil design is a major feature of the aerodynamics. Various airfoils are used at different flight regimes. Asymmetric airfoils generate lift at zero Angle of Attack, while a symmetric airfoil may be used to suit inverted flight as in an aerobatic airplane. Subsonic airfoils have a round leading edge shape, which is naturally insensitive to the angle of attack. Supersonic airfoils have much more angular shape and can have a very sharp leading edge resulting high angle of attack. A supercritical airfoil has its maximum thickness near to the leading edge. Generally transonic airfoils and supersonic airfoils designed in a way with low camber to reduce the drag divergence.

\section{Thin Airfoil Theory}

This theory is developed for the 2-D flows. On Symmetrical airfoil the centre of pressure and aerodynamic centre lies exactly one quarter of the chord at the leading edge. For a Cambered airfoil aerodynamic Centre lies exactly one quarter of chord 
backward of leading edge. The slope of the lift coefficient v/s Angle of attack is determined from the theory.

$\left(\mathrm{C}_{\mathrm{L}}=2 \pi \alpha\right)$ - For Symmetrical Airfoil

$\left(\mathrm{C}_{\mathrm{L}}=\mathrm{C}_{\mathrm{L} 0}+2 \pi \alpha\right)$ - For Cambered Airfoil

\section{Boundary Layers}

Boundary layer concept invented by Ludwig prandtl in 1904. Aerodynamic forces depend on the complicates way of the viscosity of the fluid. As fluid moves from the object the molecules next to the surface stick to the surface of object.

The molecules above the surface are slowed down in the molecules collision such that molecules stick to surface. These molecules in turn slow down in the flow. Farther one moves away from the surface the fewer the collisions affected by the object surface creating the thin layer of fluid near the surface in which velocity gradually changes from zero to free stream velocity.

This is termed as BOUNDARY LAYER that forms on the boundary of fluid.

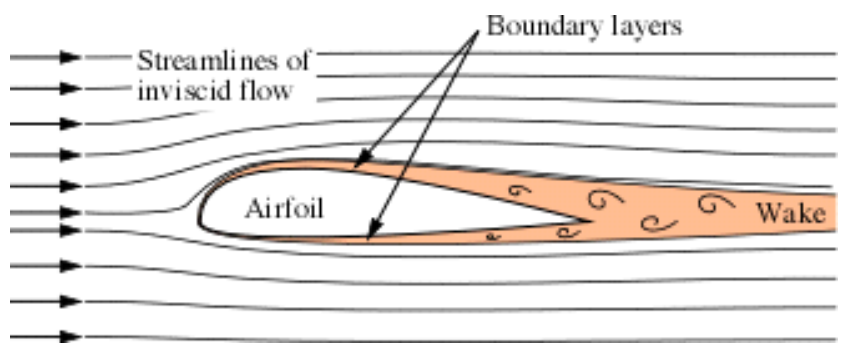

Fig 2: Boundary layer formation

An aerodynamic flow over a body can be divided into two regions:

1) A thin boundary layer that is near to the surface where the friction is dominant and the inviscid flow external to boundary layer where i.e. friction is negligible. The outer inviscid flow affects the boundary layer properties.

2) On the other hand, the boundary layer is so thin that it has no effect on the outer inviscid flow.

Boundary layer gets separated from the top surface of an airfoil if the angle of attack is greater than of the stall angle. The upper dark region that trace downstream from the separation point is the fragment of the boundary layer originally that formed on the top surface of the airfoil. The lower dark region that trace downstream from the trailing edge of the airfoil is the fragment of the boundary layer over the bottom surface.

When separated, these two dark regions termed as shear layers, and they form the upper and lower boundaries of the separated flow regime. Between the shear layers there is a dead-air region. Due to the considerable flow separation, lift of the airfoil is dramatically reduced and airfoil is stalled.
The formation of boundary layers leads to increase drag force on the surface of airfoils. Drag developed is of various types.

\section{Parasitic drag}

When body moves through the fluid medium it constitutes parasitic drag.

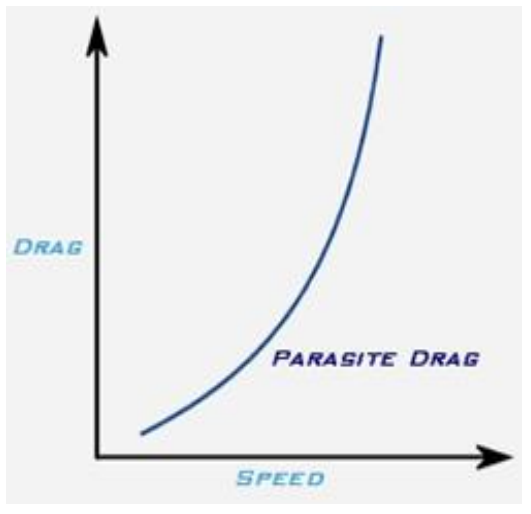

Fig 3: Parasitic drag

\section{Wave drag}

Wave drag is a force that retards the movement of airplane in supersonic and transonic regime forming the shock wave.

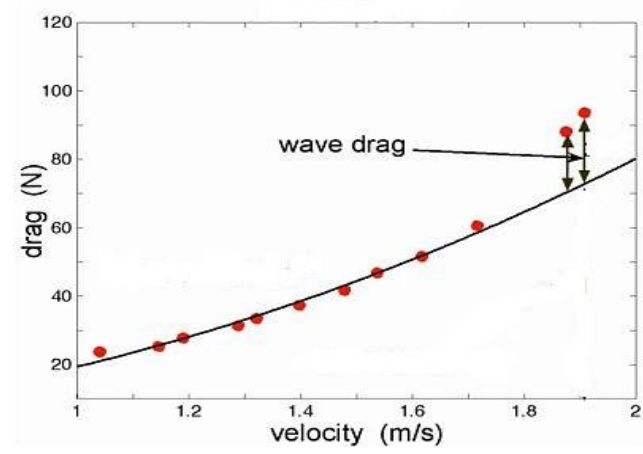

Fig 4: Wave Drag

\section{Interference drag}

Interference drag comes from the intersection of air streams that creates eddy currents, turbulence, or restricts smooth airflow.

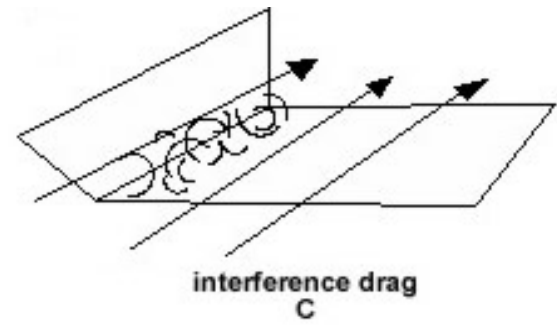

Fig 5: Interference Drag 


\section{Skin friction drag}

It is an aerodynamic resistance between the surface of aircraft and airflow.

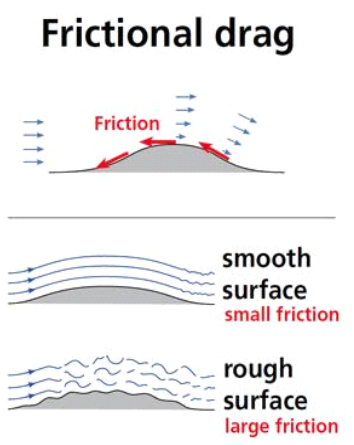

Fig 6: Skin-friction drag

\section{Form drag}

It is a portion of parasite drag generated by the aircraft due to its shape and airflow around it.

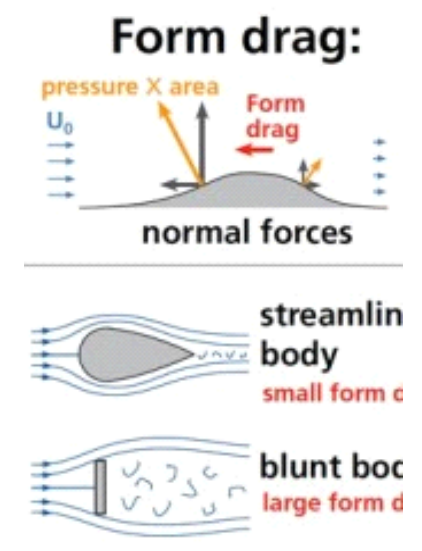

Fig 7: Form drag

\section{Induced Drag}

The drag on the airfoil which is developed from the lift

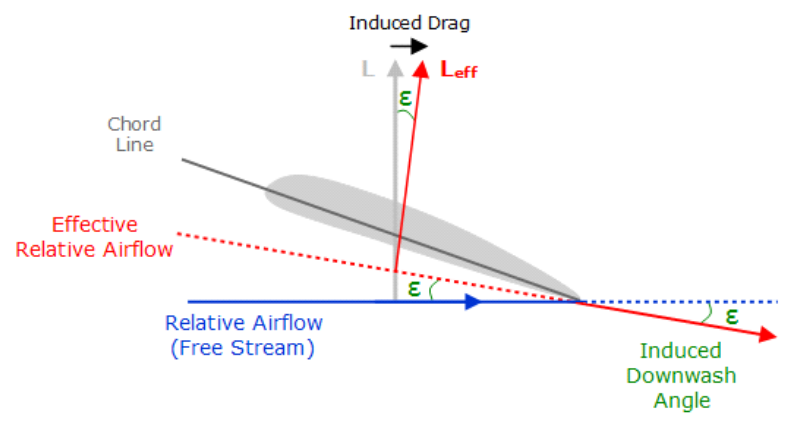

Fig 8: Induced drag

Due to the formation of drag the velocity decreases and the fuel consumption increases. This drag can be reduced by concept of Suction.

\section{Suction}

Creation of a partial vacuum by the removal of fluid in order to force it into a vacant space. Suction can be created at different positions on wing.

\section{Location of Suction Slit}

With the suitable location of slit separation can completely be prevented simultaneously the amount of pressure drag is greatly reduced owing to the absence of separation. Due to suction more pressure increases in the upper surface of an airfoil at high angle of incidence achieving maximum lift. Suction cause the point of transition in downstream direction reducing drag coefficient because the effect of laminar boundary is much less i.e. negligible when compared to turbulent boundary layer. Best results are expected when suction is kept near aerodynamic centre because the laminar boundary layer's transition starts i.e. when transition is not allowed, flow separation is prevented.

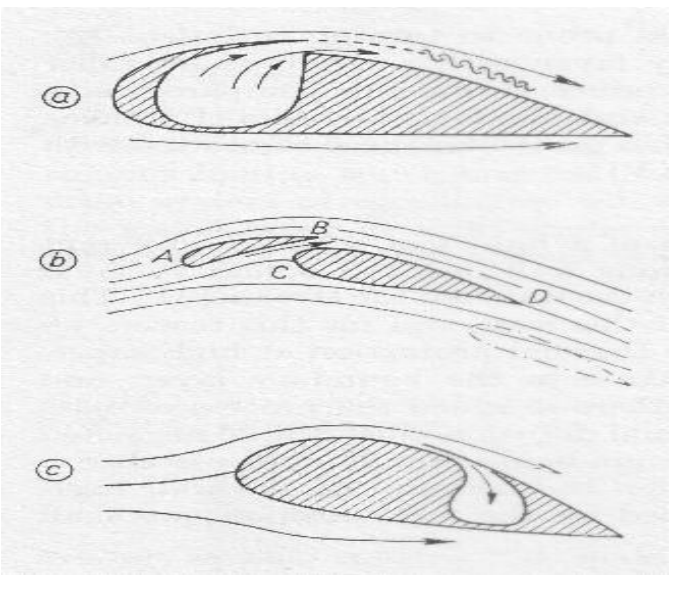

Fig 9: Various Location of Slit

\section{Design Methodology}

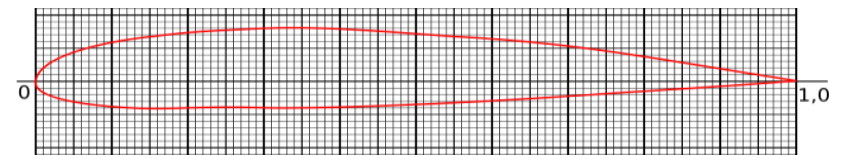

Fig 10: NACA-2412

Max thickness $12 \%$ at $29.9 \%$ chord. Max camber $2 \%$ at $40 \%$ chord

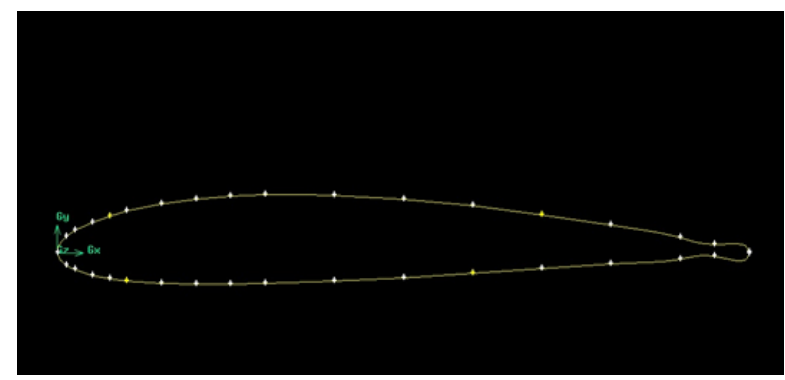

Fig 11: Airfoil Modeled in Gambit 


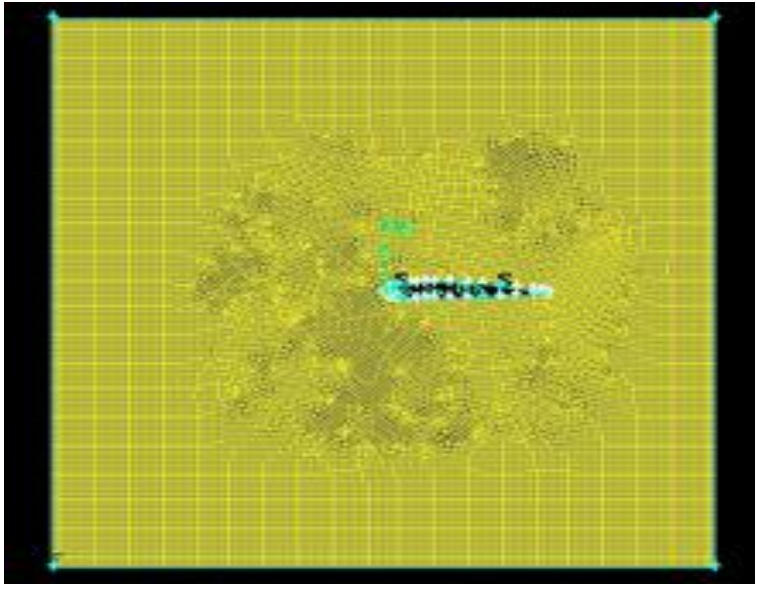

Fig 12: Airfoil Mesh

\section{Operating Conditions}

Pressure $=101325$ pa

Temperature $=288.15 \mathrm{k}$

Density $=1.23 \mathrm{~kg} / \mathrm{m}^{\wedge} 3$

Mach $=0.3-0.4$

Angle of Attack $(\alpha)=0^{\circ}, 5^{0}, 10^{0}$

\section{Governing equations}

The principal navier stokes equations for the flows considered in this work are written in vector form as:

$\frac{\partial G_{1}}{\partial x}+\frac{\partial G_{2}}{\partial y}+\frac{\partial G_{3}}{\partial Z}=\frac{\partial G_{1} y}{\partial x}+\frac{\partial G_{2} y}{\partial y}+\frac{\partial 3 y}{\partial z}$

Where G1, G2, G3 are the inviscid flux vector given by:

$G_{1}=\left[\begin{array}{c}\rho u_{1} \\ p+\rho u_{1}^{2} \\ \rho u_{1} u_{2} \\ \rho u_{1} u_{3}\end{array}\right] ; G 2=\left[\begin{array}{c}\rho u_{2} \\ \rho u_{2} u_{1} \\ P+\rho u_{2}^{2} \\ \rho u_{2} u_{3}\end{array}\right] ; \quad G_{3}=\left[\begin{array}{c}\rho u_{3} \\ \rho u_{3} u_{1} \\ \rho u_{3} u_{2} \\ p+\rho u_{3}^{2}\end{array}\right]$

$\mathrm{G}_{1} \mathrm{~V}, \mathrm{G}_{2} \mathrm{~V}, \mathrm{G}_{3} \mathrm{~V}$ are the viscous flux velocity, and is given by:

$\mathrm{G}_{1} \mathrm{y}=\left[\begin{array}{c}0 \\ \tau_{x x} \\ \tau_{x y} \\ \tau_{x z}\end{array}\right] ; \quad \mathrm{G}_{2} \mathrm{y}=\left[\begin{array}{c}0 \\ \tau_{y x} \\ \tau_{y y} \\ \tau_{y z}\end{array}\right] ; \quad \mathrm{G}_{3} \mathrm{y}=\left[\begin{array}{c}0 \\ \tau_{z x} \\ \tau_{z y} \\ \tau_{z z}\end{array}\right]$

$\mathrm{L}=\mathrm{N} \cos \alpha-\mathrm{A} \sin \alpha ; \mathrm{D}=\mathrm{N} \sin \alpha+\mathrm{A} \cos \alpha$

\section{Results and discussion}

Numerical Simulations were performed using FLUENT, to capture the overall flow features of suction Airfoil at various position of the suction. This process is carried out at various angle of attacks $\left(0^{0}, 5^{0}, 10^{\circ}\right)$ and at various speeds of the flow. Contours are studied for the variation of $\mathrm{L} / \mathrm{D}$ ratios. The contours drawn at various speeds and angle of attacks are similar. From the report the $\mathrm{L} / \mathrm{D}$ ratios are calculated and tabulated.

\section{At $0^{\circ}$ Angle of Attack}
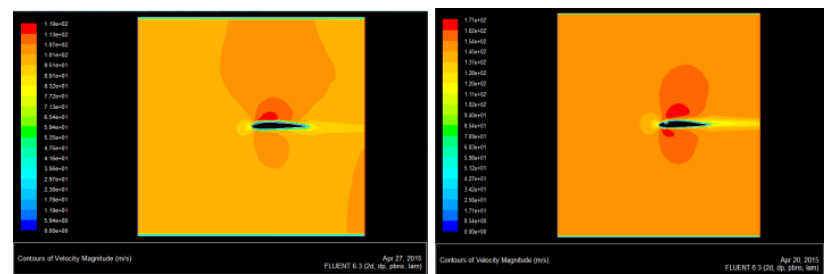

Fig 13: Velocity contour at $0^{0} \mathrm{Fig}$ 14: Velocity contour at $0^{0}$
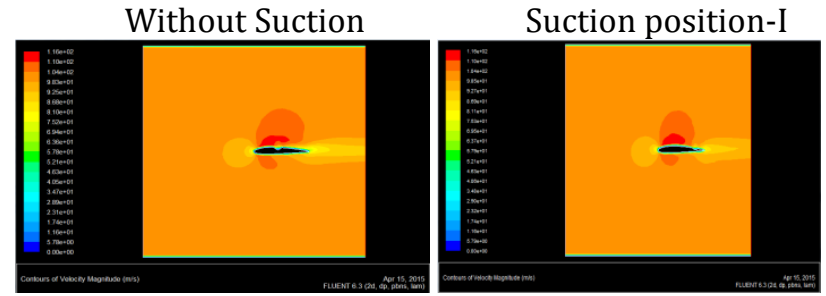

Fig 15: Velocity contour at $0^{0} \mathrm{Fig}$ 16: Velocity contour at $0^{0}$

Suction position-II

Suction position-III

Table 1: $\mathrm{L} / \mathrm{D}$ ratios at $0^{0} \mathrm{AOA}$

\begin{tabular}{|l|c|c|c|c|}
\hline L $D$ Ratio & Normal at $0^{\circ}$ & Suction 1 at $0^{\circ}$ & Suction 2 at $0^{\circ}$ & Suction 3 at $0^{\circ}$ \\
\hline $\mathrm{V}=80 \mathrm{~m} / \mathrm{s}$ & 295.720 & 236.746 & $\mathbf{3 6 7 . 2 4 6}$ & 249.078 \\
\hline $\mathrm{V}=100 \mathrm{~m} / \mathrm{s}$ & 367.630 & 295.893 & $\mathbf{4 6 0 . 0 0 3}$ & 311.354 \\
\hline $\mathrm{V}=150 \mathrm{~m} / \mathrm{s}$ & 554.400 & 443.760 & $\mathbf{6 8 8 . 4 3 6}$ & 466.888 \\
\hline
\end{tabular}

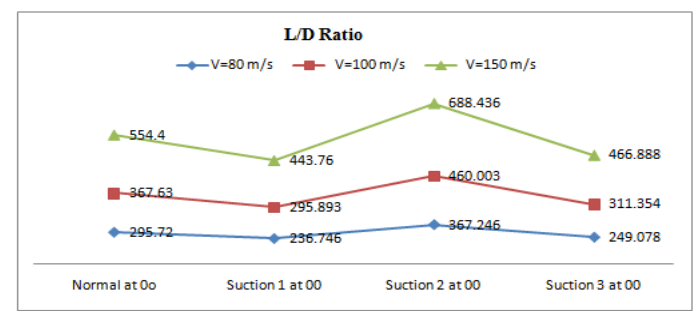

Graph 1: L/D ratios at $0^{0} \mathrm{AOA}$

\section{At $5^{0}$ Angle of Attack}

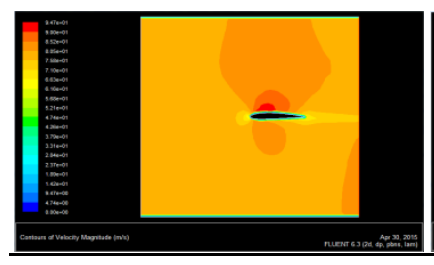

Fig 17: Velocity contour at $5^{0}$ Fig 18: Velocity contour at $5^{0}$ Without Suction
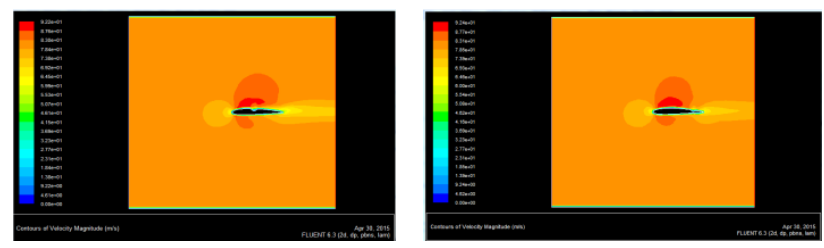

Fig 19: Velocity contour at $5^{0}$ Fig 20: Velocity contour at $5^{0}$ Suction position-II

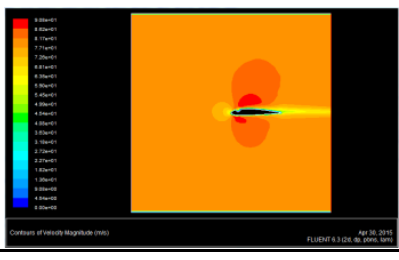

Suction position-I Suction position-III 
Table 2: $\mathrm{L} / \mathrm{D}$ ratios at $5^{0} \mathrm{AOA}$

\begin{tabular}{|c|c|c|c|c|}
\hline LD Ratio & Normal at $10^{\circ}$ & Suction 1 at $10^{\circ}$ & Suction 2 at $10^{\circ}$ & Suction 3 at $10^{\circ}$ \\
\hline $\mathrm{V}=80 \mathrm{~m} / \mathrm{s}$ & 5.573 & 5.533 & 5.581 & 5.539 \\
\hline $\mathrm{V}=100 \mathrm{~m} / \mathrm{s}$ & 5.563 & 5.560 & 5.599 & 5.565 \\
\hline $\mathrm{V}=150 \mathrm{~m} / \mathrm{s}$ & 5.557 & 5.596 & 5.622 & 5.600 \\
\hline
\end{tabular}

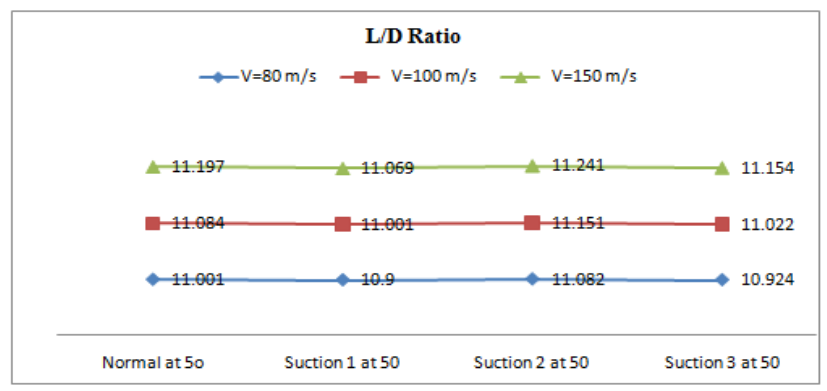

Graph 2: $\mathrm{L} / \mathrm{D}$ ratios at $5^{0} \mathrm{AOA}$

\section{At $10^{\circ}$ Angle of Attack}
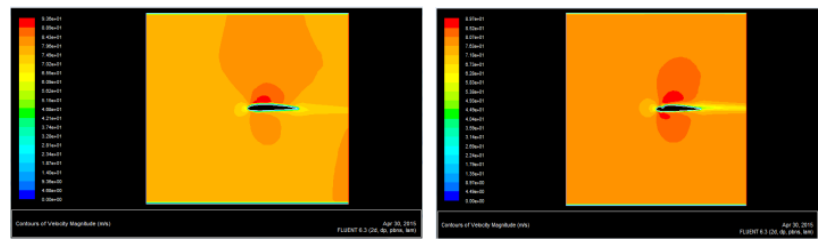

Fig21: Velocity contour at $10^{\circ}$ Fig22: Velocity contour at $10^{\circ}$ Without Suction Suction position-I
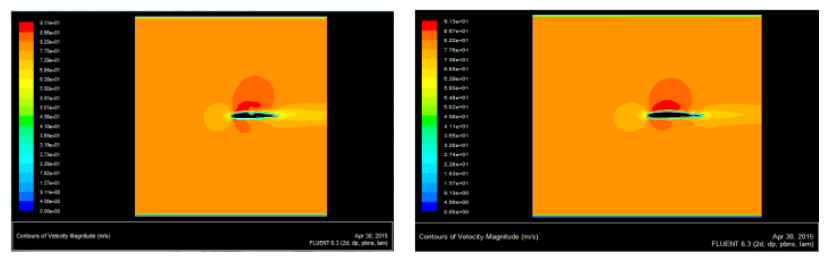

Fig23:Velocity contour at $10^{\circ} \mathrm{Fig} 24$ : Velocity contour at $10^{\circ}$ Suction position-II Suction position-III

Table 3: $\mathrm{L} / \mathrm{D}$ ratios at $10^{\circ} \mathrm{AOA}$

\begin{tabular}{|l|c|c|c|c|}
\hline L/D Ratio & Normal at $10^{\circ}$ & Suction 1 at $10^{\circ}$ & Suction 2 at $10^{\circ}$ & Suction 3 at $10^{\circ}$ \\
\hline $\mathrm{V}=80 \mathrm{~m} / \mathrm{s}$ & 5.573 & 5.533 & 5.581 & 5.539 \\
\hline $\mathrm{V}=100 \mathrm{~m} / \mathrm{s}$ & 5.563 & 5.560 & 5.599 & 5.565 \\
\hline $\mathrm{V}=150 \mathrm{~m} / \mathrm{s}$ & 5.557 & 5.596 & 5.622 & 5.600 \\
\hline
\end{tabular}

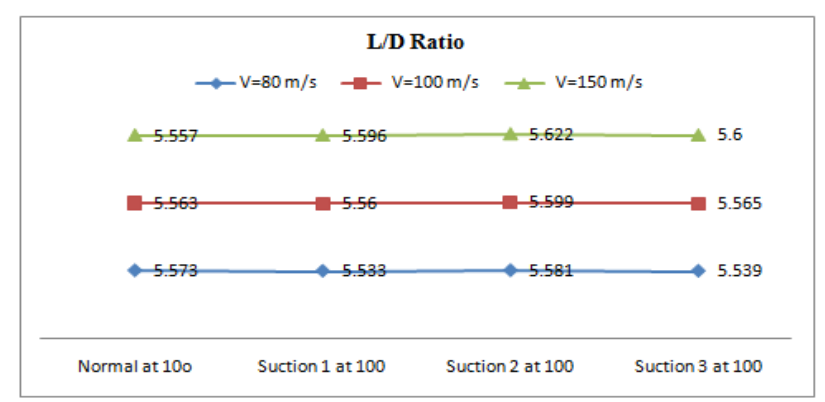

Graph 3: L/D ratios at $10^{0} \mathrm{AOA}$
The present study was to compare the aerodynamic characteristics of the normal airfoil with suction in the boundary layer. Both the normal and suction in the boundary layer of airfoils are simulated with the same run conditions and the results are shown above in terms of contours, L/D ratio. From the contours, at $0^{\circ}$, $5^{\circ}, 10^{\circ}$ angle of attack the velocity magnitude over an airfoil has different pattern compared to the normal airfoil. The flow is leaving after reaching suction in the boundary layer of an airfoil trailing edge smoothly without creating vortices compared to normal airfoil. From the results values, it is observed that lift force of airfoil with suction into the boundary layer of an airfoil is increased and drag force decreased compared to normal airfoil. The L/D ratio suggest that the suction to the airfoil performance is better than normal airfoil at $0^{\circ}, 5^{\circ}, 10^{\circ}$ angle of attack.

\section{Conclusion}

From the contours of different velocity at the $0^{\circ} 5^{\circ}, 10^{\circ}$ angle of attack simulation, it is observed that due to the effect of suction slit, lift to drag ratio increased compared to the normal. Comparing to three different suction slit position, suction at position 2 have an effect of increase of L/D ratio to that of normal airfoil. We conclude that we get a high $\mathrm{L} / \mathrm{D}$ ratio at suction position 2 comparing of all the position to that of the normal airfoil, at $80 \mathrm{~m} / \mathrm{s}, 100 \mathrm{~m} / \mathrm{s} 150 \mathrm{~m} / \mathrm{s}$ velocities at an angle of attack of $0^{0}$ and $5^{0}$. While there is a decrease in L/D ratio at an angle of attack of $10^{\circ}$ with increase in velocity of the normal airfoil. But with the help of suction to the airfoil there is a increase in L/D ratio with increase of velocity, this will further increase the change of increase in $L / D$ ratio even at higher Angle of attack.

\section{Nomenclature}

$\mathrm{C}_{\mathrm{N}}=$ Coefficient of Normal Force,

$\mathrm{C}_{\mathrm{A}}=$ Coefficient of Axial Force,

$\mathrm{N}=$ Normal Force,

$\mathrm{A}=$ Axial Force,

$\alpha=$ Angle of attack

\section{References}

John D. Anderson (2012), Fundamentals of Aerodynamics, $5^{\text {th }}$ Edition, Tata McGraw Hill Education Private Limited, New Delhi.

Herrmann Schlichting . Klaus Gersten (1996), Boundary layer theory, $8^{\text {th }}$ revised edition, Bochum.

Singiresu S. Rao(2010), Finite Element Method in Engineering, $5^{\text {th }}$ Edition, united states of America.

Douglas, J F, Gasiorek, J M and Swaffield, J A, Fluid Mechanics, 3rd Edition, Longman, Singapore Publishers Ltd, Singapore, (1998).

Thwaites, B (1960), Incompressible Aerodynamics, Dover Publications, New York

Roberson, J A and Crowe, C T (1993), Engineering Fluid Mechanics, 5th Edition, Boston Houghton Mifflin

Howel, J and Le Good, G The Influence of Aerodynamic Lift on High Speed Stability SAE Paper 1999-01-0651, (1999).

Ota, T, Itasaka, M (1976), A separated and reattached flow on a blunt flat plate, ASME Trans Journal of Fluid Engineering, Vol 98, pp 79-84. 